\title{
Application of Photocurrent Model on Polymer Solar Cells Under Forward Bias Stress
}

Rizzo, Antonio; Torto, Lorenzo; Wrachien, Nicola; Corazza, Michael; Krebs, Frederik C; Gevorgyan, Suren; Cester, Andrea

Published in:

IEEE Journal of Photovoltaics

Link to article, DOI:

10.1109/JPHOTOV.2016.2603841

Publication date:

2017

Document Version

Peer reviewed version

Link back to DTU Orbit

Citation (APA):

Rizzo, A., Torto, L., Wrachien, N., Corazza, M., Krebs, F. C., Gevorgyan, S., \& Cester, A. (2017). Application of Photocurrent Model on Polymer Solar Cells Under Forward Bias Stress. IEEE Journal of Photovoltaics, 6(6), 1542-1548. https://doi.org/10.1109/JPHOTOV.2016.2603841

\section{General rights}

Copyright and moral rights for the publications made accessible in the public portal are retained by the authors and/or other copyright owners and it is a condition of accessing publications that users recognise and abide by the legal requirements associated with these rights.

- Users may download and print one copy of any publication from the public portal for the purpose of private study or research.

- You may not further distribute the material or use it for any profit-making activity or commercial gain

- You may freely distribute the URL identifying the publication in the public portal 


\title{
Application of photocurrent model on polymer solar cells under forward bias stress
}

\author{
Antonio Rizzo, Student Member, IEEE, Lorenzo Torto, Nicola Wrachien, Michael Corazza, \\ Frederik C. Krebs, Suren. A. Gevorgyan, Andrea Cester, Senior Member, IEEE
}

\begin{abstract}
We performed constant current stress at forward bias on organic heterojunction solar cells. We measured current voltage curves in both dark and light at each stress step to calculate the photocurrent. An existing model applied to photocurrent experimental data allows the estimation of several parameters such as generation, recombination, dissociation rate and nearly zero field voltage within the active layer as a function of the stress time. The analysis of extrapolated parameters shows that the stress mainly affects the recombination rate of the polaron charge transfer states.
\end{abstract}

Index Terms - Heterojunctions, Organic Semiconductors, Annealing, Stress, Current, Solar energy, Photovoltaic cells, Rollto-Roll.

\section{INTRODUCTION}

$\mathrm{T}$ HE device efficiency and the speed of fabrication process of polymer solar cells were significantly improved during the last few years and many research group are today looking at them with a growing interest as a low-cost and ecosustainable alternative to common solar cells in some applications [1]-[4]. In order to extract the performance parameters (efficiency, fill factor, short circuit current and open circuit voltage) of samples under accelerated stress, the most common way is to carry out periodic current-voltage (IV) measurements [5]-[8]. However, even though these common figures of merit are immediate indicators of the cell performance, they cannot give a comprehensive picture of the several physical parameters, which are critical for the cell energy conversion efficiency. Among them, are the mobility, the polaron separation efficiency, the built-in potential, etc. A more advanced analysis is therefore needed in order to have better understanding of the complex behavior of such parameters. The accurate extrapolation and analysis of photocurrent [9]-[11] and the study of the impedance spectroscopy [12],[13] - for example - represent further investigation tools in organic heterojunction solar cells that can reveal the behavior of important physical parameters such

"This work was supported in part by Padova University project CPDA141417/14: "Characterization and Reliability study of Organic Solar Cells for low-cost and flexible applications".

A. Rizzo, L. Torto, N. Wrachien, A. Cester are with the University of Padova, 35131 Padova, Italy (e-mail: andrea.cester@dei.unipd.it).

S.A. Gevorgyan, M. Corazza, F.C. Krebs are with Ris $\varnothing$ National Laboratory for Sustainable Energy, Technical University of Denmark, Roskilde, Denmark. as generation rate, polaron charge transfer states separation and recombination rate, built-in potential and carrier lifetime.

During the operational life of a photovoltaic module, several factor may concurrently contribution in the loss of the cell performances. For example, light exposure, high temperature, non-optimal electrical operative conditions and electrostatic discharge (ESD) are just a few of the possible reasons that lead to the cell degradation during its operating conditions. In particular, light exposure is especially critical in flexible organic photovoltaic. In fact, in standard solar cell module, clouds and dust are the main source of shading; however, in organic photovoltaic module also the architectonic application on curved surfaces is responsible for partially shadowing cells. Thus, illumination conditions might be not optimal and not uniform over the whole module, due to architectonic constrains. These conditions may force the shaded or partially shaded cells in the module to operate in forward or reverse bias. This may negatively affect the reliability of the whole panel.

In this work, we analyzed the evolution of the above cited parameters during accelerated electrical stress in forward bias condition. We estimated them by applying an existing photocurrent model and we investigated the parameters behavior during the stress. Forward bias stress emulates the situation of a partially shaded module, when a cell is brought to forward bias due to the module connections.

\section{EXPERIMENTAL AND DEVICES}

We assembled the $1-\mathrm{cm}^{2}$ active area cells in roll-to-roll compatible process with a mini-roll coater [14]. The front electrode (Flextrode) is composed of an Ag grid, PEDOT:PSS and $\mathrm{ZnO}$, and the back electrode consists of PEDOT:PSS and the Ag grid encloses the blend of P3HT:PCBM

We applied forward bias accelerated stress at $70 \mathrm{~mA} / \mathrm{cm}^{2}$, $100 \mathrm{~mA} / \mathrm{cm}^{2}$, and $150 \mathrm{~mA} / \mathrm{cm}^{2}$ constant currents (CCS) in dark and under illumination. We systematically paused the stress to monitor devices conditions by means of I-V measurements in both light and dark. We performed I-V with a voltage from $-2.5 \mathrm{~V}$ to $1 \mathrm{~V}$. The total stress time was $7 \mathrm{~h}$. An Agilent E5263A Parameter analyzer was used for both the I-V measurements and the stress. We illuminated the cells by using a white LED because the measurement noise floor generated by white LED is much lower, compared to a xenon solar simulator. Besides, we used white LEDs because of its very low content in UV wavelengths and low power 
dissipation. These properties of the LEDs allow a reduction of the degradations induced by the light source (UV and thermal effects) so that we could better isolate the sole effect of the CCS on the devices. We calibrated the LED intensity to reach a cell illumination level equivalent to that obtained by a solar simulator at 1 sun. We verified that the short circuit current under LED illumination and solar simulator illumination at 1 sun have the same values, as well as all other important figure of merits (fill-factor, efficiency, etc). Finally, we used a PVE300 spectral responsivity analyzer to perform External Quantum Efficiency (EQE) measurements.

\section{RESUlTS AND DISCUSSIONS}

\section{A. Figures of merit degradation during CCS}

The devices we build reach an average efficiency of 1.2$1.3 \%$ with an open voltage of $0.55 \mathrm{~V}$ and an average short circuit current density of $5 \mathrm{~mA} / \mathrm{cm}^{2}$ [2]. Although the efficiency is lower than other polymeric organic solar cell devices reported in literature [15]-[18], we underline that we do not process these devices under controlled environment. Indeed, we use a semi-automatic mini-roll coater under environmental air. The usage of a glove-box and a spin-coater would probably increase such efficiency, allowing the reaching of higher performances. However, glove-box processing and devices spin-coating are not the real conditions applied during roll-to-roll mass production. Thus, both the uncontrolled environment and the not fully automatized process may lead to a efficiency reduction. On the other hand, such devices are closer to the cells built on real photovoltaic modules since they undergo the same processing [1].

Figs. 1a and $1 \mathrm{~b}$ show the evolution of the short circuit current density $\left(\mathrm{J}_{\mathrm{SC}}\right)$ and normalized efficiency $(\eta)$ as a function of the stress time, respectively. In Fig. 1a we notice that, independent of the applied stress current, all the CCS induced a monotonic decrease of the $\mathrm{J}_{\mathrm{SC}}$ and the rate of decay was increasing with the stress current. Noticeably, for the larger stress current value $\left(150 \mathrm{~mA} / \mathrm{cm}^{2}\right)$ under illumination (open red triangles), the decay rate seems to slow down during the last stress steps, likely due to an annealing process, which partially compensates the CCS-induced degradation. In fact, the cells temperature reached up to $90^{\circ} \mathrm{C}$ at $150 \mathrm{~mA} / \mathrm{cm}^{2}$ [8]. The self-heating induced by power dissipation during the stress, induced a partial recovery of the short circuit current density, at least for a stress as long as 25000 seconds.

The efficiency shows a behavior similar to the short circuit current. In Fig. 1b we plot the efficiency evolution normalized to the fresh value. Although efficiency generally decreases with increasing the stress time and current, there is a small recovery during the last stress steps for high stress current values $\left(150 \mathrm{~mA} / \mathrm{cm}^{2}\right)$, more accentuated under illumination, due to the additional temperature increase induced by the light exposure. This is due to the high temperature reached during the stress, which results in partial annealing of the damage generated in the first part of the stress.

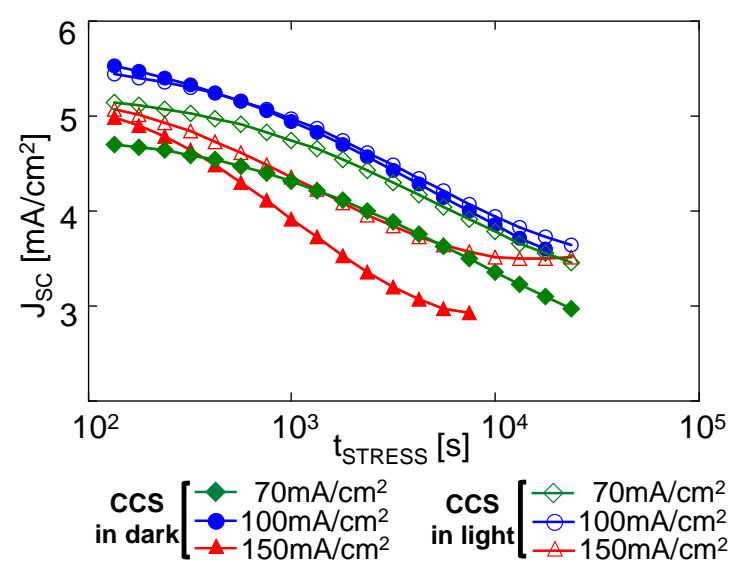

(a)

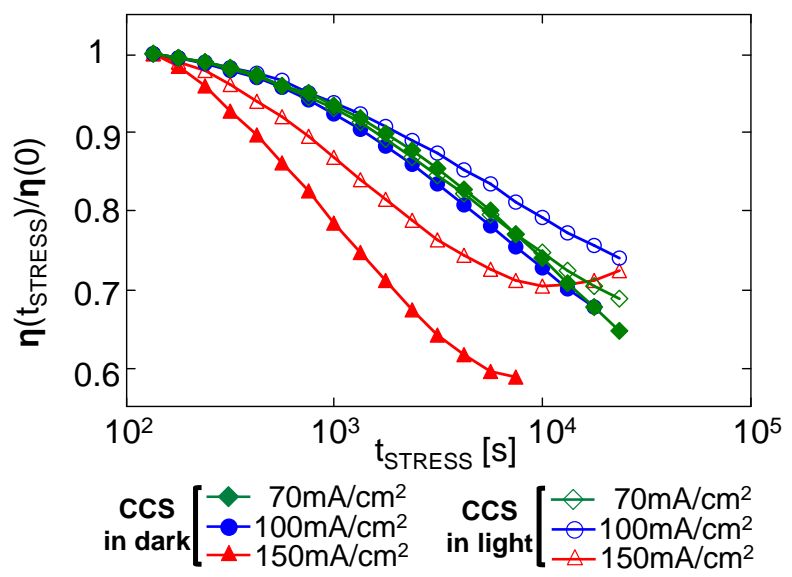

(b)

Fig. 1. Short circuit current density (a) and normalized efficiency (b) as a function of stress time, during CCS.

\section{B. Photocurrent model description}

To further investigate the mechanisms behind the degradation/recovery during CCS, we calculated the photocurrent as the difference of light and dark currents:

$\mathrm{J}_{\mathrm{PH}}=\mathrm{J}_{\text {LIGHT }}-\mathrm{J}_{\text {DARK }}$

Where $\mathrm{J}_{\mathrm{PH}}$ is the photocurrent, $\mathrm{J}_{\mathrm{LIGHT}}$ is the current density measured under illumination and $\mathrm{J}_{\text {DARK }}$ the current measure in dark. In order to obtain an accurate value of the photocurrent we also corrected the experimental data to account for the parasitic series resistance. The series resistance value was calculated by means of impedance spectroscopy [19], and it was continuously monitored during the stress. In all the devices, the series resistance ranges between $10 \Omega$ and $15 \Omega$, and it is almost constant during the stress. Remarkably, the current measured in our cells may approach $8 \mathrm{~mA}$, which may produce a voltage drop as large as $0.12 \mathrm{~V}$ in the non-active regions (contacts, zinc oxide layer, etc.) This means that for a given voltage, the actual voltage drop across the active layer might be significantly different when the $\mathrm{I}-\mathrm{V}$ is measured in dark and light conditions. For this reason, we corrected the I-V curves before subtracting $\mathrm{J}_{\text {DARK }}$ to $\mathrm{J}_{\text {LIGHT. }}$ Fig. 2 shows the effect of the series resistance in the dark and the light I-V and the extrapolated photocurrent. 


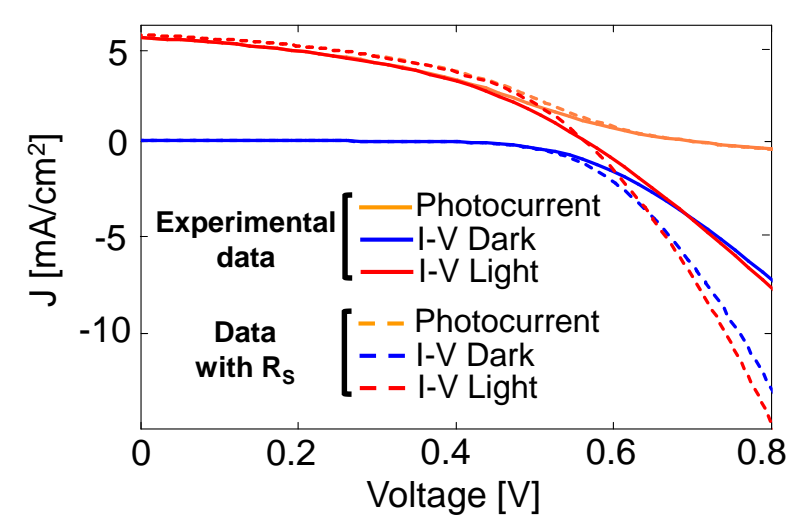

Fig. 2. Current density in dark/light and photocurrent, without (solid lines) and with (dashed lines) series resistance $R_{S}$. In this specific case $R_{S}=12 \Omega$. The contribution of the series resistance is particularly relevant at high forward bias.

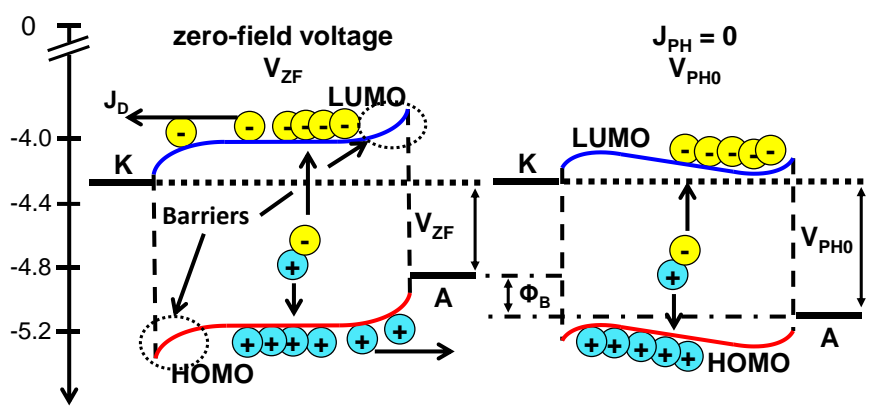

(a)

(b)

Fig. 3. (a) band bending at nearly zero-field voltage $\left(\mathrm{V}_{\mathrm{ZF}}\right)$ and (b) at $\mathrm{V}_{\mathrm{PHO}}$ where the photocurrent is zero. $\Phi_{\mathrm{B}}$ represents the additional potential required to reach zero photocurrent.

After series resistance correction, in order to fit to the experimental data we adopted the model proposed in [9], which expresses the photocurrent as the superposition of two contributions:

$J_{P H}=q G L\left[\operatorname{coth}\left(\frac{V-V_{Z F}}{2 V_{T}}\right)-\frac{2 V_{T}}{V-V_{Z F}}\right] P\left(\frac{V-V_{Z F}}{L}\right)+J_{D}$

Equation (2) includes the Sokel-Hughes model for photoconductivity in insulators [20], the Braun-Onsager dissociation probability of polarons charge transfer states (P) [21] and a diffusion current contribution $\left(\mathrm{J}_{\mathrm{D}}\right)$ firstly introduced by Ooi et al. [10],[11] and then employed also by Limpinsel et al. [9]. In (2), $\mathrm{G}$ is the average generation rate of polaron pairs (assumed constant all over the active layer); $\mathrm{q}$ is the elementary charge; $\mathrm{L}$ is the thickness of the active layer; $\mathrm{V}_{\mathrm{T}}$ is the thermal voltage; $\mathrm{V}$ is the actual voltage drop across the active layer; $\mathrm{V}_{\mathrm{ZF}}$ is the voltage corresponding to the nearly zero electric field within the active layer. The function $\mathrm{P}$ accounts for the separation probability of a bound polaron pair into two free polarons and it is electric field dependent. Finally, $J_{D}$ is the current density contribution, which correspond to the current at $\mathrm{V}=\mathrm{V}_{\mathrm{ZF}}$. $\mathrm{V}_{\mathrm{ZF}}$ substitution to the built-in voltage and $J_{D}$ current density account for the nonideal contacts and the non-constant electric field in the close proximity of the electrodes. Indeed, the Sokel-Hughes model considers photoconductivity in insulator where there is no charge accumulation. Thus, Ooi and Limpinsel included $\mathrm{J}_{\mathrm{D}}$ and $\mathrm{V}_{\mathrm{ZF}}$ terms in their models to take account for bend bending due to charge accumulation at interfaces. We invite the reader to refer to reference [9]-[11] for further details.

Following the adopted model, Fig. 3 represents a qualitative band diagram that helps understanding the carrier dynamics within the active layer at different operating voltages. Contact interfaces bend due to non-ideal alignment between the blend and the electrodes Fermi levels. The band bending generates two barriers at the contact interfaces preventing electrons flow toward the anode and holes flow toward the cathode. In other words, we may figure the electrodes as partially selective contacts [11]. The higher the barrier, the stronger is the selectivity of the contact. Fig. 3a describes the situation that occurs when the external applied potential keeps the bulk of the active layer at a nearly zero-field condition. We refer to this applied bias as $\mathrm{V}_{\mathrm{ZF}}$. In other words, within the active layer there is a quasi-flat band condition. Then, dissociated charges (electrons/holes) flow to the electrodes by drift in the region close to the contacts and by diffusion in the bulk of the active layer [9][10]. However, since there are selective interfaces that generate barriers, they do not flow equally to anode and cathode but they mostly reach the electrode with lower potential barrier. Thus, the photocurrent generated at $\mathrm{V}_{\mathrm{ZF}}$ is not zero, giving raise to $J_{D}$. The absolute value of $J_{D}$ relates to both the amount of free carriers generated and the height of the barriers. Fig. $3 b$ shows the band bending when the photocurrent is zero. We refer as $\mathrm{V}_{\mathrm{PH} 0}$ to the voltage at which the photocurrent is zero. In this case, the model predicts that the band bending within the active layer compensates the barriers height. Thus, by applying $\mathrm{V}_{\mathrm{PHO}}$, electrons and hole can equally flow to both cathode and anode, resulting in a zero photocurrent. Although a more sophisticated modeling could improve the accuracy of $\mathrm{V}_{\mathrm{PH} 0}$ and $\mathrm{V}_{\mathrm{ZF}}$, as a first approximation, we can figure that the additional potential (defined $\Phi_{\mathrm{B}}$ in Fig. 3) required to move from the quasi flat band (Fig. 3a) to the zero-photocurrent condition (Fig. 3b) is correlated to the sum of the band bending at the two interfaces. We may estimate $\Phi_{B}$ as the difference between $\mathrm{V}_{\mathrm{PH} 0}$ and $\mathrm{V}_{\mathrm{ZF}}$.

\section{Parameter extraction}

By fitting the photocurrent with (2), we extrapolated the parameters: $J_{D}, V_{Z F}, \Phi_{B}, G, k_{R E C}$ and $k_{S E P}$ as a function of the stress time, with $\mathrm{k}_{\mathrm{REC}}$ and $\mathrm{k}_{\mathrm{SEP}}$ the polaron recombination and separation rates respectively affecting the separation probability $\mathrm{P}$ as described by the Braun-Onsager theory [21].

Fig. 4 shows an example of the fitting results on a cell that underwent CCS at $70 \mathrm{~mA} / \mathrm{cm}^{2}$ under light. We observe that when (2) is applied to photocurrent, it gives a very good fit of experimental data in both forward and reverse bias voltages. In Fig. 4, the series resistance used to account for contacts interfaces and other drops is $12 \Omega \cdot \mathrm{cm}^{2}$ (measured by impedance spectroscopy), and it is compatible with the series resistance measured by other research groups [13], [22].

Figs. 5 and 6 show the evolution of $J_{\mathrm{D}}$ and $\Phi_{\mathrm{B}}$ respectively. 
$\mathrm{J}_{\mathrm{D}}$ keeps decreasing until last step of stress. We must correlate the decrease of $J_{\mathrm{D}}$ with the decreasing behavior of $\Phi_{\mathrm{B}}$, which is the difference between $\mathrm{V}_{\mathrm{PHO}}$ and $\mathrm{V}_{\mathrm{ZF}}$. The higher is $\Phi_{\mathrm{B}}$ the larger are the band bending - and in turn the sum of voltage drops - at the interfaces. The reduction of $\Phi_{\mathrm{B}}$ is a clear signature that the voltage drops and the barrier height near the contact are reducing. In turn, this contributes to reduction of the intensity of the diffusion current.

Of course, such a reduction could originate also from the mobility reduction, which affects the diffusion constant by the Einstein relation. However, we extrapolated the evolution of the mobility from the dark current, assuming a Space Charge Limited conduction through the organic layer, and we verified that mobility remains practically unchanged during stress with a value of $\mu=7.6 \cdot 10^{-3} \mathrm{~cm}^{2} \mathrm{~V}^{-1} \mathrm{~s}^{-1}$. For this reason, we can neglect the effect of mobility in the diffusion current.

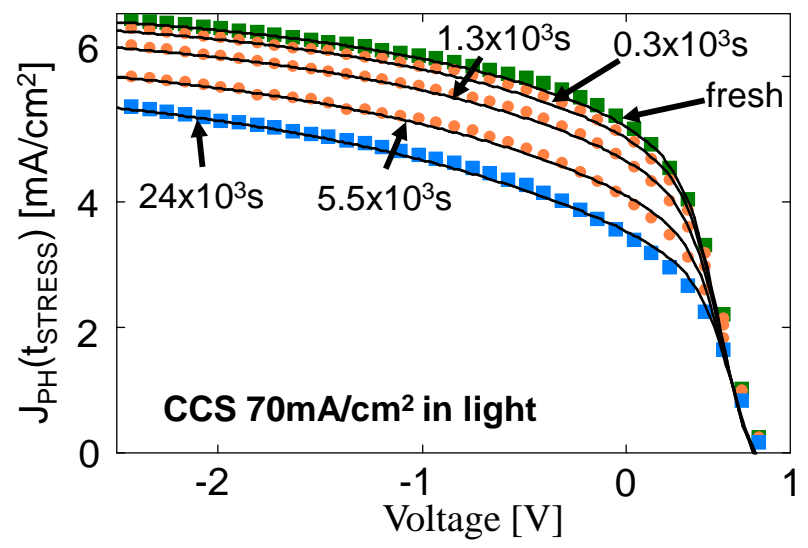

Fig. 4. Photocurrent experimental data (symbols) and fitting results of model (2) (lines) corrected with a series resistance of $12 \Omega \cdot \mathrm{cm}^{2}$. The shown stress steps are from a CCS performed at $70 \mathrm{~mA} / \mathrm{cm}^{2}$ in light.

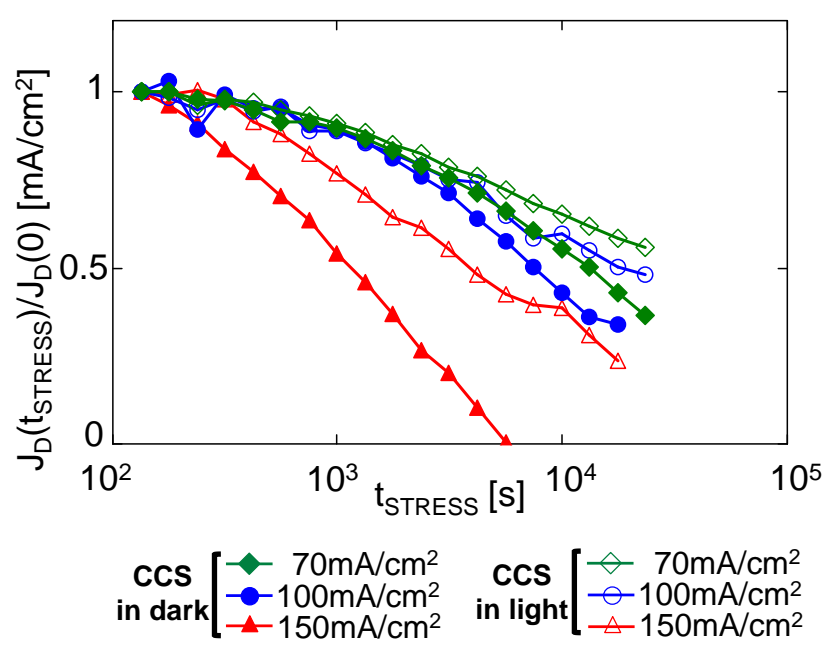

Fig. 5. Diffusion current $J_{D}$ normalized to fresh value as a function of stress time.
Fig. 7 shows the correlation between the diffusion current $\mathrm{J}_{\mathrm{D}}$ and the potential $\Phi_{\mathrm{B}}$. Each correlation curve is a straight line. All curves are enclosed into a well-defined band, confirming that higher $\Phi_{\mathrm{B}}$ corresponds to higher $\mathrm{J}_{\mathrm{D}}$. Furthermore, as $\Phi_{\mathrm{B}}$ decreases during the stress, there is a corresponding reduction of $\mathrm{J}_{\mathrm{D}}$. In particular during CCS at 150 $\mathrm{mA} / \mathrm{cm}^{2}$ in dark (filled red triangles), when $\Phi_{\mathrm{B}}$ tends towards zero during last stress steps, $\mathrm{J}_{\mathrm{D}}$ gets close to zero as well. In fact, the disappearing of the barrier generates a non-selective contact and, in turn, the diffusion current at nearly zero-field voltage $\left(\mathrm{V}_{\mathrm{ZF}}\right)$ vanishes.

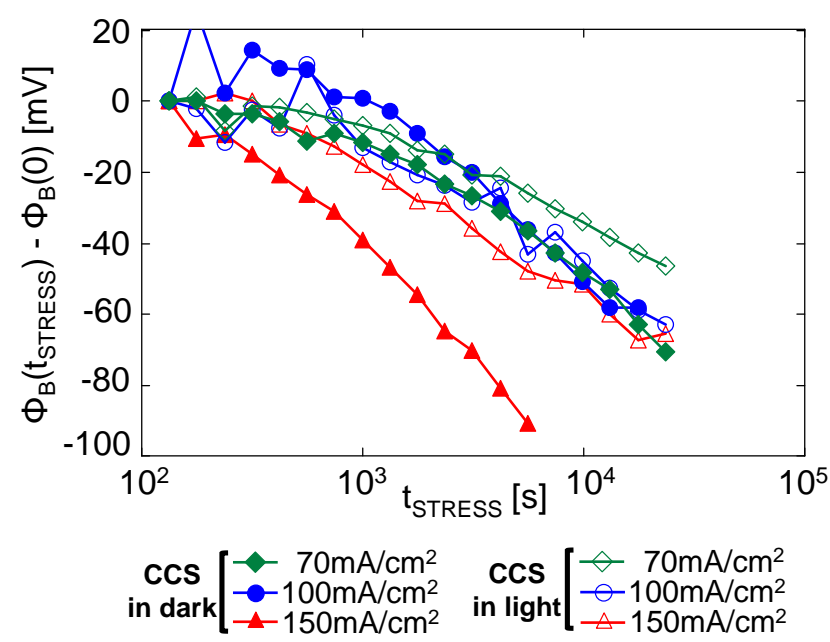

Fig. 6. Potential $\Phi_{\mathrm{B}}$ as a function of the stress time.

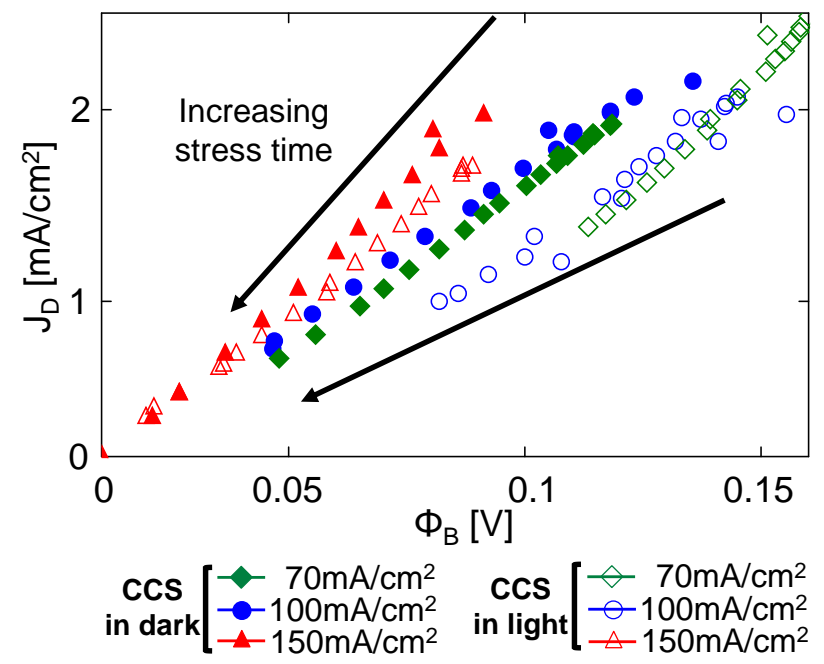

Fig. 7. Correlation graph between the diffusion current $J_{D}$ and the voltage $\Phi_{B}$ with stress time. 


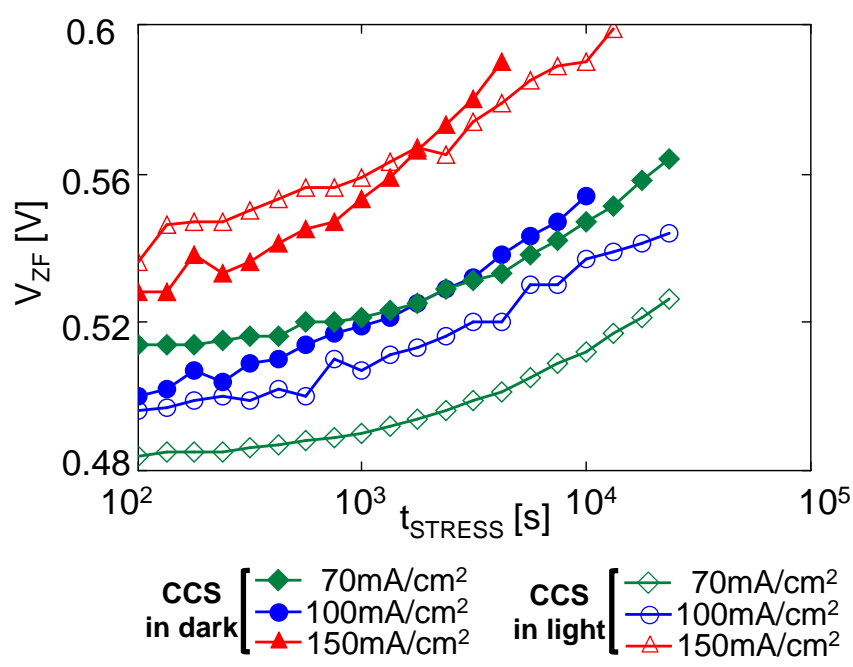

Fig. 8. Nearly zero-field voltage $\mathrm{V}_{\mathrm{ZF}}$ as a function of the stress time.

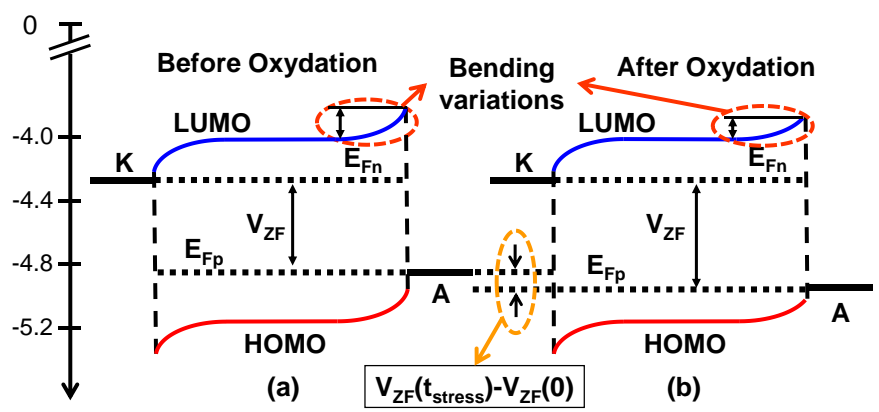

Fig. 9. Qualitative band banding at the nearly zero field voltage $V_{\mathrm{ZF}}$ on a fresh device (a) and after that the oxidation process increased the P3HT doping (b).

The decrease of $\Phi_{\mathrm{B}}$ must be associated with the increase of $\mathrm{V}_{\mathrm{ZF}}$ shown in Fig. 8. We related the variation of $\mathrm{V}_{\mathrm{ZF}}$ during stress to the oxidation of P3HT [23], [24]. In fact, it has been already observed in literature, that the exposure of $\mathrm{P} 3 \mathrm{HT}$ to oxygen increases the p-type doping, shifting the P3HT Fermi level toward the HOMO band. In turn, this reduces the band bending in proximity of the anode, as qualitatively described by the sketch in Fig. 9. Among the causes for the increase in P3HT doping, oxygen and moisture embedded during the fabrication process can be the primary candidates. In addition, they may also permeate the encapsulation layers reaching the active layer during device operation [25], [26]. The electrical stress may accelerate the oxidation process, increasing the effective doping and thus increasing the $\mathrm{V}_{\mathrm{ZF}}$ value. In fact, the higher the CCS current the higher the oxidation rate is. This may come from both the increase of the applied voltage required to maintain the imposed forward current and the temperature increase due to self-heating that can thermally assist the chemical reactions. Incidentally, in a previous work we measured that temperature may increase up to $90{ }^{\circ} \mathrm{C}$ during CCS at $150 \mathrm{~mA} / \mathrm{cm}^{2}$ in dark [8].

The illumination during CCS produces only marginal changes, despite the additional device heating expected from the illumination. However, the presence of light during stress decreases the voltage required to set the CCS current. This, in turn, slightly decreases the power dissipation, partially compensating the additional heating induced by illumination.
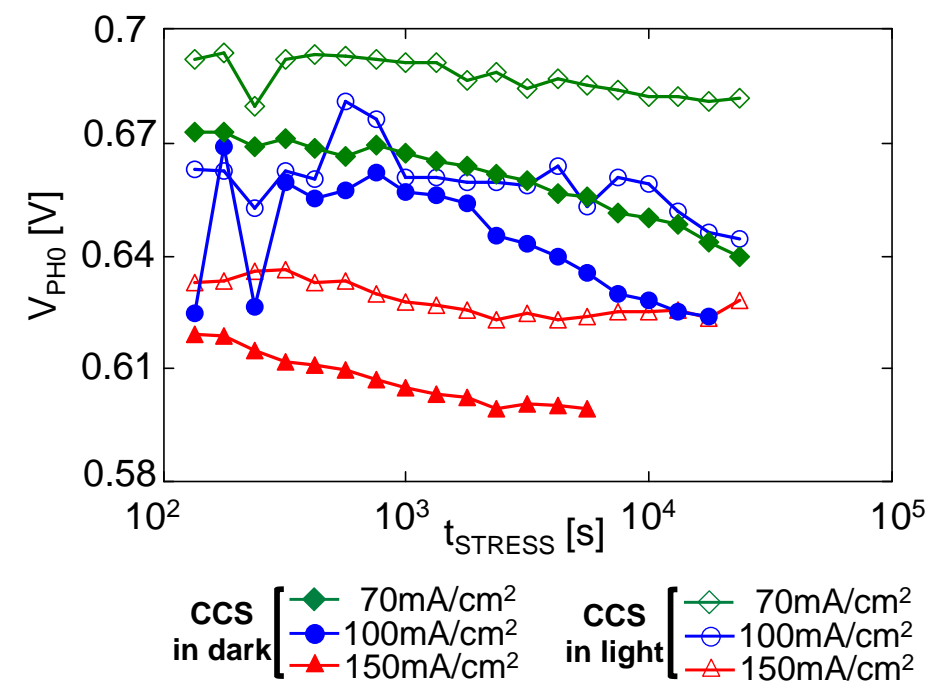

Fig. 10. Voltage $\mathrm{V}_{\mathrm{PHO}}$ (corresponding to $\mathrm{J}_{\mathrm{PH}}=0 \mathrm{~mA} / \mathrm{cm}^{2}$ ) as a function of the stress time.

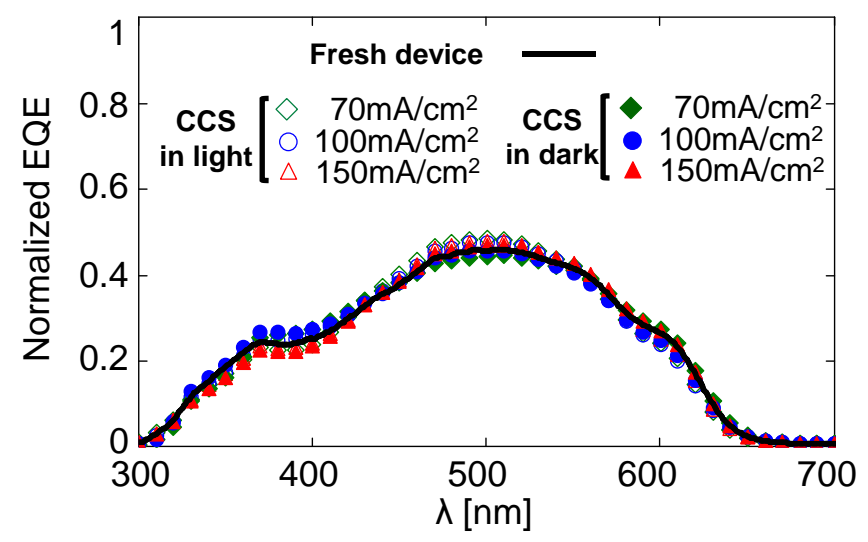

Fig. 11. Normalized External Quantum Efficiency (EQE) comparison between a fresh cell (black line) and cells that underwent CCS at 70, 100 and $150 \mathrm{~mA} / \mathrm{cm}^{2}$ both in light and in dark (symbols).

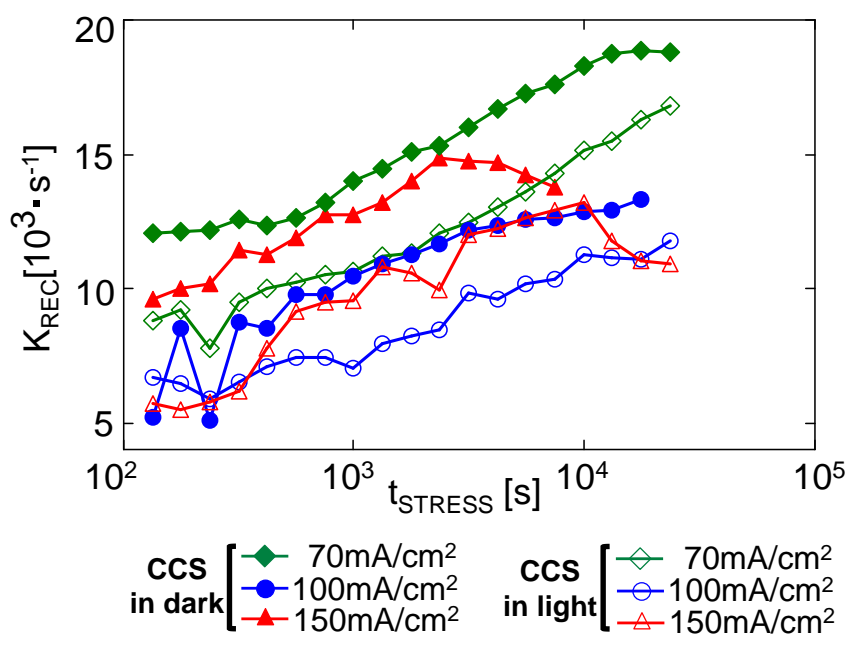

Fig. 12. Recombination rate of polaron charge transfer states with time of stress. 
Fig. 10 shows the voltage corresponding to the zero of the photocurrent as a function of the stress time. $\mathrm{V}_{\mathrm{PH} 0}=\mathrm{V}_{\mathrm{ZF}}+\Phi_{\mathrm{B}}$ decreases with stress time due to the higher decrease of the potential $\Phi_{\mathrm{B}}$ compared to the increase of $\mathrm{V}_{\mathrm{ZF}}$.

When comparing the evolution of $\mathrm{J}_{\mathrm{SC}}$ in Fig. 1a and $\mathrm{J}_{\mathrm{D}}$ in Fig. 5 during stress, we observe a very different behavior. For instance, during CCS at $150 \mathrm{~mA} / \mathrm{cm}^{2}$ under illumination $\mathrm{J}_{\mathrm{D}}$ keeps always decreasing down to almost zero, while $\mathrm{J}_{\mathrm{SC}}$ slowly decreases with a saturating behavior after 10000 seconds. This clearly indicates that the decay of the short circuit current density cannot originate only from $\mathrm{J}_{\mathrm{D}}$, but also the generation rate and dissociation probability play important roles. However, the generation rate of polaron pairs G extrapolated from photocurrent is constant with stress time, independently on the CCS current or illumination conditions. We calculated that $\mathrm{G}=1.08 \pm 0.07 \cdot 10^{21} \mathrm{~cm}^{-3} \mathrm{~s}^{-1}$. EQE measurements further confirms that $\mathrm{G}$ is constant. Fig. 11 shows the EQE as a function of radiation wavelength normalized on its area, for both fresh and stressed cells. No significant variations are observed, indicating that the absorption spectrum shape of the blend is constant during CCS. It is worth clarifying again that the reader should bear in mind that the absolute EQE for degraded sample is lower than for the fresh sample and here the normalized data is presented instead for better indication of no changes in the curve shape and thus in the absorption. This is a signature that no changes occur to the generation rate of bounded polaron pairs, confirming the idea that the stress does not affect $\mathrm{G}$.

Since $\mathrm{G}$ is almost constant, the variation of the short circuit current must derive from the change of polaron recombination and/or separation rates. Following the Braun-Onsager theory the separation rate is [21]:

$$
\begin{gathered}
k_{S E P}=k_{S E P 0} \frac{J_{1}(2 \sqrt{-2 b})}{2 \sqrt{-2 b}} \\
k_{S E P 0}=\frac{3 q\langle\mu\rangle}{4 \pi a^{3} \varepsilon} e^{-\frac{\Delta E}{k T}} \quad b=\frac{q^{3} F}{8 \pi \varepsilon k^{2} T^{2}}
\end{gathered}
$$

Where $\mathrm{J}_{1}$ is the first order Bessel function, $\mathrm{q}$ is the elementary charge, $a$ is the average molecular distance, $\langle\mu\rangle$ is the average mobility $\left(7.6 \cdot 10^{-3} \mathrm{~cm}^{2} \mathrm{~V}^{-1} \mathrm{~s}^{-1}\right.$ in our case), $\varepsilon$ is the electric permittivity, $\Delta \mathrm{E}$ is the exciton binding energy, $\mathrm{kT}$ is the thermal energy potential, $\mathrm{F}$ is the electric field. $\mathrm{k}_{\mathrm{SEP}}$ represents the charge transfer exciton separation rate at zero electric field.

Because $\mathrm{k}_{\mathrm{SEP} 0}$ is primarily dependent on the mobility, we assumed $\mathrm{k}_{\mathrm{SEP} 0}$ almost constant. Its value obtained for all the CCSs at different currents is $\mathrm{k}_{\mathrm{SEP} 0}=9.9 \pm 2.5 \cdot 10^{3} \mathrm{~s}^{-1}$ calculated with $a=1 \mathrm{~nm}$ and $\varepsilon=3 \varepsilon_{0}$. Instead, Fig. 12 shows the evolution of $k_{\mathrm{REC}}$, i.e the polaron recombination rate, which increases by increasing stress time in most of the samples. In some cases, such as during the CCS at $150 \mathrm{~mA} / \mathrm{cm}^{2}$ under illumination, $\mathrm{k}_{\mathrm{REC}}$ start decreasing after 10000 seconds, i.e., the same time when the short circuit current saturates to the minimum value and the efficiency starts experiencing a partial recovery. Tentatively, we may ascribe the decrease of the recombination rate with the annealing of some morphological defects responsible for the exciton quenching, due to the high temperature reached during stress.

Again, this confirms that the recombination rate severely affects the cells performances, and it is one of the dominant effects driving the variation of the short circuit current and the cell efficiency, as well.

\section{CONCLUSIONS}

In this work, we showed that the polaron recombination rate is one of the major reasons for the cell degradation during constant current stress in forward bias condition. Besides, our data and the model show that a correlation exists between the band banding at the interfaces and the photocurrent, and these bending contribute to cell performances together with the polaron recombination rate.

Even though the applied model is very simple and qualitative, it is still suitable for finding a relation between the cell degradation and the variation of some parameters, such as the exciton separation probability or the contact barrier heights. Of course, some limits still exist. For instance, it is possible to extract the cumulative effects of the barrier height at the contacts, but it is not possible to distinguish and separate the contribution of the single barrier. For sure, the development of a more quantitative and complete model is worthy for a more detailed and accurate analysis, for quantifying better the role of interface degradation and the mechanisms behind the photocurrent generation. This will be our next step in future works.

\section{REFERENCES}

[1] F. C. Krebs, "Roll-to-roll fabrication of monolithic large-area polymer solar cells free from indium-tin-oxide" Sol. Energy Mater. Sol. Cells, vol. 93, no. 9, pp. 1636-1641, 2009.

[2] H. F. Dam and F. C. Krebs, "Simple roll coater with variable coating and temperature control for printed polymer solar cells" Sol. Energy Mater. Sol. Cells, vol. 97, pp. 191-196, 2012.

[3] D. Angmo, S. a. Gevorgyan, T. T. Larsen-Olsen, R. R. Søndergaard, M. Hösel, M. Jørgensen, R. Gupta, G. U. Kulkarni, and F. C. Krebs, "Scalability and stability of very thin, roll-to-roll processed, large area, indium-tin-oxide free polymer solar cell modules," Org. Electron. physics, Mater. Appl., vol. 14, no. 3, pp. 984-994, 2013.

[4] F. C. Krebs, "Air stable polymer photovoltaics based on a process free from vacuum steps and fullerenes," Sol. Energy Mater. Sol. Cells, vol. 92, no. 7, pp. 715-726, 2008.

[5] M. O. Reese, S. a. Gevorgyan, M. Jørgensen, E. Bundgaard, S. R. Kurtz, D. S. Ginley, D. C. Olson, M. T. Lloyd, P. Morvillo, E. a. Katz, A. Elschner, O. Haillant, T. R. Currier, V. Shrotriya, M. Hermenau, M. Riede, K. R. Kirov, G. Trimmel, T. Rath, O. Inganäs, F. Zhang, M. Andersson, K. Tvingstedt, M. Lira-Cantu, D. Laird, C. McGuiness, S. Gowrisanker, M. Pannone, M. Xiao, J. Hauch, R. Steim, D. M. Delongchamp, R. Rösch, H. Hoppe, N. Espinosa, A. Urbina, G. YamanUzunoglu, J. B. Bonekamp, A. J. J. M. Van Breemen, C. Girotto, E. Voroshazi, and F. C. Krebs, "Consensus stability testing protocols for organic photovoltaic materials and devices," Sol. Energy Mater. Sol. Cells, vol. 95, no. 5, pp. 1253-1267, 2011.

[6] E. Dunlop, T. Sample, G. Bardizza, and A. Pozza, "Analysis Based on IV Curve Changes of Organic Photovoltaic Mini-Modules Subjected to Degradation under Different Temperature and Humidity Conditions," 29th Eur. Photovolt. Sol. Energy Conf. Exhib., pp. 1523-1529, Nov. 2014.

[7] M. R. Lilliedal, A. J. Medford, M. V. Madsen, K. Norrman, and F. C. Krebs, "The effect of post-processing treatments on inflection points in current-voltage curves of roll-to-roll processed polymer photovoltaics," Sol. Energy Mater. Sol. Cells, vol. 94, no. 12, pp. 2018-2031, Dec. 2010. 
[8] A. Cester, A. Rizzo, A. Bazzega, N. Lago, J. Favaro, M. Barbato, N. Wrachien, S. A. Gevorgyan, M. Corazza, and F. C. Krebs, "Effects of constant voltage and constant current stress in PCBM:P3HT solar cells," Microelectron. Reliab., vol. 55, no. 9-10, pp. 1795-1799, Aug. 2015.

[9] M. Limpinsel, A. Wagenpfahl, M. Mingebach, C. Deibel, and V. Dyakonov, "Photocurrent in bulk heterojunction solar cells," Phys. Rev. B, vol. 81, no. 8, p. 085203, Feb. 2010.

[10] Z. E. Ooi, T. L. Tam, A. Sellinger, and J. C. deMello, "Field-dependent carrier generation in bulk heterojunction solar cells," Energy Environ. Sci., vol. 1, no. 2, p. 300, Jul. 2008.

[11] Z. E. Ooi, R. Jin, J. Huang, Y. F. Loo, A. Sellinger, and J. C. deMello, "On the pseudo-symmetric current-voltage response of bulk heterojunction solar cells," J. Mater. Chem., vol. 18, no. 14, p. 1644, Mar. 2008.

[12] M. Glatthaar, N. Mingirulli, B. Zimmermann, T. Ziegler, R. Kern, M. Niggemann, a. Hinsch, and a. Gombert, "Impedance spectroscopy on organic bulk-heterojunction solar cells," Phys. Status Solidi Appl. Mater. Sci., vol. 202, no. 11, pp. 125-127, 2005.

[13] T. Kuwabara, Y. Kawahara, T. Yamaguchi, and K. Takahashi, "Characterization of inverted-type organic solar cells with a $\mathrm{ZnO}$ layer as the electron collection electrode by ac impedance spectroscopy.," ACS Appl. Mater. Interfaces, vol. 1, no. 10, pp. 2107-10, Oct. 2009.

[14] J. E. Carlé, T. R. Andersen, M. Helgesen, E. Bundgaard, M. Jorgensen, and F. C. Krebs, "A laboratory scale approach to polymer solar cells using one coating/printing machine, flexible substrates, no ITO, no vacuum and no spincoating," Sol. Energy Mater. Sol. Cells, vol. 108, pp. 126-128, 2013.

[15] N. Ćelić, E. Pavlica, M. Borovšak, J. Strle, J. Buh, J. Zavašnik, G. Bratina, P. Denk, M. Scharber, N. S. Sariciftci, and D. Mihailovic, "Factors determining large observed increases in power conversion efficiency of P3HT:PCBM solar cells embedded with Mo6S9-xIx nanowires" Synth. Met., vol. 212, pp. 105-112, 2016.

[16] D. Chen, A. Nakahara, D. Wei, D. Nordlund, and T. P. Russell, "P3HT/PCBM Bulk Heterojunction Organic Photovoltaics: Correlating Efficiency and Morphology," 2010.

[17] V. Vohra, K. Kawashima, T. Kakara, T. Koganezawa, I. Osaka, K. Takimiya, and H. Murata, "Efficient inverted polymer solar cells employing favourable molecular orientation," Nat. Photonics, vol. 9, no. 6, pp. 403-408, May 2015.

[18] I. Etxebarria, J. Ajuria, and R. Pacios, "Solution-processable polymeric solar cells: A review on materials, strategies and cell architectures to overcome 10\%," Org. Electron., vol. 19, pp. 34-60, 2015.

[19] A. Rizzo, A. Cester, L. Torto, M. Barbato, N. Wrachien, N Lago, M. Corazza, F.C. Krebs, S. A. Gevorgyan, "Effects of Current Stress and Thermal Storage on polymeric heterojunction P3HT:PCBM solar cell", IEEE-International Reliability Physics Symposium - IRPS 2016, p. 3C2-1 - 3C-2-6, Pasadena, CA, USA, April 17-21, 2016

[20] R. Sokel, "Numerical analysis of transient photoconductivity in insulators," J. Appl. Phys., vol. 53, no. 11, p. 7414, Nov. 1982.

[21] C. L. Braun, "Electric field assisted dissociation of charge transfer states as a mechanism of photocarrier production," J. Chem. Phys., vol. 80, no. 9, pp. 4157-4161, 1984.

[22] G. Perrier, R. de Bettignies, S. Berson, N. Lemaître, and S. Guillerez, "Impedance spectrometry of optimized standard and inverted P3HTPCBM organic solar cells," Sol. Energy Mater. Sol. Cells, vol. 101, pp. 210-216, Jun. 2012.

[23] A. Guerrero, P. P. Boix, L. F. Marchesi, T. Ripolles-Sanchis, E. C. Pereira, and G. Garcia-Belmonte, "Oxygen doping-induced photogeneration loss in P3HT:PCBM solar cells," Sol. Energy Mater. Sol. Cells, vol. 100, pp. 185-191, May 2012.

[24] J. Schafferhans, A. Baumann, A. Wagenpfahl, C. Deibel, and V. Dyakonov, "Oxygen doping of P3HT:PCBM blends: Influence on trap states, charge carrier mobility and solar cell performance," Org. Electron., vol. 11, no. 10, pp. 1693-1700, Oct. 2010.

[25] M. Jørgensen, K. Norrman, and F. C. Krebs, "Stability/degradation of polymer solar cells," Sol. Energy Mater. Sol. Cells, vol. 92, no. 7, pp. 686-714, Jul. 2008.

[26] M. Jørgensen, K. Norrman, S. a. Gevorgyan, T. Tromholt, B. Andreasen, and F. C. Krebs, "Stability of polymer solar cells," Adv. Mater., vol. 24, no. 5, pp. 580-612, 2012.

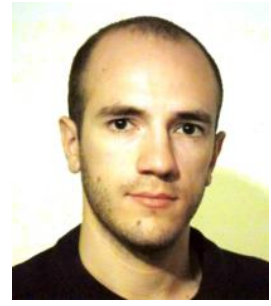

Antonio Rizzo (M'15) was born in Legnago, Italy, in 1990. He received the M.S. degree in electronic engineering from the University of Padua, Padua, Italy in 2014 where he is currently enrolled in a Ph.D in organic electronics, particularly on organic photovoltaic devices.

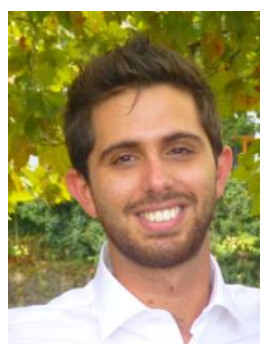

Lorenzo Torto (M'16) obtained the bachelor degree in 2013 in Information Engineering and the MS degree in 2016 in electronic engineering at the department of Information Engineering at the University of Padova. His interests are in characterization, reliability and modeling of polymeric solar cells.

Nicola Wrachien was born in Treviso, Italy, in 1982. He received the degree (magna cum laude) in electronic engineering in 2006 from the University of Padova, Italy, and the $\mathrm{PhD}$ in Information Engineering in 2010, working on advanced non-volatile memories. He currently holds a postdoc position working on organic semiconductor devices.

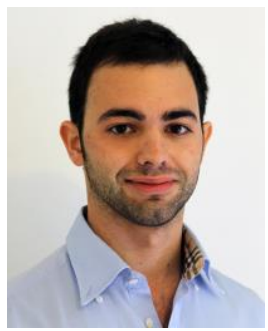

Michael Corazza is a PhD student at the Technical University of Denmark. He received his master degree in electronic engineering in 2013 at the "Università degli studi di Padova". He has been working with photovoltaics since 2012, first with inorganic and then with organic PVs. Research interests involve degradation of devices and their advanced characterization (electron microscopes, mechanical tests, etc.).

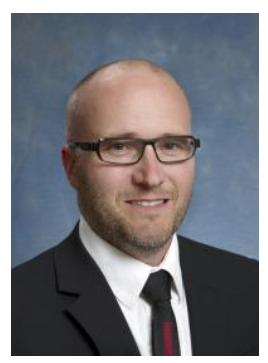

Frederik C. Krebs received a $\mathrm{PhD}$ from the Technical University in 2000. Since 2000, he has been working on polymer solar cells and was appointed full professor in 2010. His research interests are printed solar cells with low environmental impact and the interplay between different disciplines that enable use of polymer solar cells in the energy system.

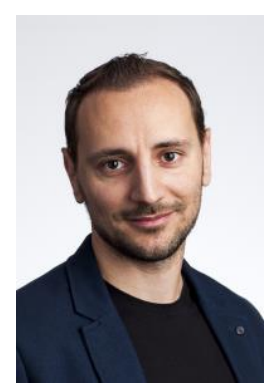

Suren A. Gevorgyan is a senior scientist at the Technical University of Denmark. He received his $\mathrm{PhD}$ from Technical University of Denmark in 2010. From the early years of his career, Suren has been working on organic photovoltaics and specializing in characterization and stability of the technology. Research interests involve new generation thin film PVs, device engineering, durability, standard testing. 


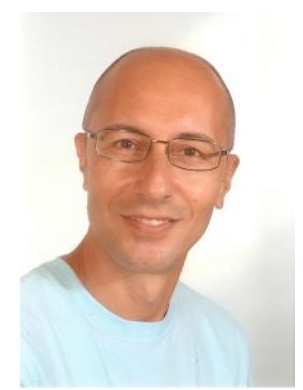

Andrea Cester (M'98, SM'13) is Associate Professor at the Department of Information Engineering, University of Padova (Italy). $\mathrm{He}$ is the author/coauthor of more than 180 papers published in international journals and conference proceedings. His research activities ranges: the characterization, reliability study, and modeling of organic electronic devices, photovoltaic devices, RF-MEMS switches for reconfigurable antenna arrays. 